07.2

\title{
Спектральный сдвиг излучения квантово-каскадного лазера под действием управляющего напряжения
}

\author{
(C) А.В. Бабичев ${ }^{1}$, Д.А. Пашнев ${ }^{2}$, А.Г. Гладышев ${ }^{1}$, А.С. Курочкин ${ }^{1}$, Е.С. Колодезный ${ }^{1}$, Л.Я. Карачинский ${ }^{1,3,4}$, \\ И.И. Новиков ${ }^{1,3,4}$, Д.В. Денисов ${ }^{5}$, L. Boulley ${ }^{6}$, Д.А. Фирсов ${ }^{2}$, Л.Е. Воробьев ${ }^{2}$, \\ Н.А. Пихтин ${ }^{4}$, А. Bousseksou ${ }^{6}$, А.Ю. Егоров ${ }^{1}$
}

${ }^{1}$ Санкт-Петербургский национальный исследовательский университет информационных технологий, механики и оптики (Университет ИТМО), Санкт-Петербург, Россия

${ }^{2}$ Санкт-Петербургский политехнический университет Петра Великого, Санкт-Петербург, Россия

${ }^{3} \mathrm{OOO} \mathrm{„Коннектор} \mathrm{Оптикс“,} \mathrm{Санкт-Петербург,} \mathrm{Россия}$

${ }^{4}$ Физико-технический институт им. А.Ф. Иофрфе РАН, Санкт-Петербург, Россия

${ }^{5}$ Санкт-Петербургский государственный электротехнический университет „ЛЭТИ“, Санкт-Петербург, Россия

${ }^{6}$ Center of Nanoscience and Nanotechnology (C2N), UMR9001 CNRS, University Paris Sud, University Paris Saclay, France E-mail: a.babichev@mail.ioffe.ru

Поступило в Редакцию 17 июля 2019г.

В окончательной редакции 23 июля 2019 г.

Принято к публикации 23 июля 2019 г.

\begin{abstract}
Продемонстрировано перераспределение интенсивностей коротковолновых и длинноволновых компонент в пределах полосы усиления в спектре генерации квантово-каскадного лазера спектрального диапазона 7-8 $\mu \mathrm{m}$ под действием управляющего напряжения. При увеличении напряжения с 10.5 до $18.2 \mathrm{~V}$ длина волны, соответствующая максимуму интенсивности лазерного излучения, смещается примерно на $200 \mathrm{~nm}$. Максимальная ширина спектра генерации составляет порядка $300 \mathrm{~nm}$ (при температуре $80 \mathrm{~K}$ ). Гетероструктура квантово-каскадного лазера выращена методом молекулярно-пучковой эпитаксии. Использована конструкция активной области на основе двухфононной схемы опустошения нижнего уровня с применением гетеропары твердых растворов $\mathrm{In}_{0.53} \mathrm{Ga}_{0.47} \mathrm{As} / \mathrm{In}_{0.52} \mathrm{Al}_{0.48} \mathrm{As}$, согласованных по параметру кристаллической решетки с подложкой InP.
\end{abstract}

Ключевые слова: сверхрешетки, квантово-каскадный лазер, эпитаксия, фосфид индия.

DOI: 10.21883/PJTF.2019.22.48643.17985

Перестраиваемые квантово-каскадные лазеры (ККЛ) спектрального диапазона 7-8 $\mu \mathrm{m}$ требуются для ряда применений, в числе которых дистанционный газоанализ [1] и медицинские приложения [2]. Наиболее распространенными методами перестройки длины волны излучения ККЛ являются изменение температуры кристалла (перестройка на уровне 0.5\%) [3,4] и использование геометрии внешнего резонатора (перестройка порядка 15\%) [5]. Дополнительный метод увеличения диапазона перестройки - использование активных областей с широким спектром усиления [6], в том числе гетерогенных активных областей [7]. Альтернативные подходы к формированию перестраиваемых ККЛ основаны на использовании многосекционных конструкций кристалла [8], конструкций с независимой токовой накачкой [9], а также перестраиваемых под действием управляющего напряжения ККЛ [10-13].

В настоящей работе представлены результаты исследования ККЛ спектрального диапазона 7-8 $\mu \mathrm{m}$ в конструкции активной области на основе двухфононной схемы опустошения нижнего уровня с длиной волны максимума интенсивности излучения, перестраиваемой управляющим напряжением.

Гетероструктура ККЛ была выращена компанией „Коннектор Оптикс, на промышленной установке моле- кулярно-пучковой эпитаксии Riber 49 [14,15]. В качестве подложки использовались пластины InP с ориентацией (001), легированные серой до уровня $n=1 \cdot 10^{17} \mathrm{~cm}^{-3}$. Активная область включала 50 каскадов на основе конструкции с двухфононной схемой опустошения нижнего уровня [16-18]. При формировании каскадов была использована гетеропара $\mathrm{In}_{0.53} \mathrm{Ga}_{0.47} \mathrm{As} / \mathrm{In}_{0.52} \mathrm{Al}_{0.48} \mathrm{As}$. Толщина верхней обкладки волновода (слоя InP) составила $0.75 \mu \mathrm{m}\left(n=1 \cdot 10^{17} \mathrm{~cm}^{-3}\right)$. В качестве контактных слоев применялись слои $\operatorname{In}_{0.53} \mathrm{Ga}_{0.47} \mathrm{As}$ толщиной 100 и $20 \mathrm{~nm}$ с уровнями легирования $1 \cdot 10^{17}$ и $1 \cdot 10^{19} \mathrm{~cm}^{-3}$ соответственно.

При формировании кристалла ККЛ была использована конструкция мезы с затравом в подложку [19]. Ширина и длина резонатора составили $22 \mu \mathrm{m}$ и $1.5 \mathrm{~mm}$ соответственно. Отражающее и антиотражающее покрытия на сколотые грани лазера не наносились. Монтаж кристалла производился подложкой на медный теплоотвод при помощи индиевого припоя.

Детектирование оптического сигнала проводилось с помощью фотоприемника $\mathrm{HgCdTe}$, охлаждаемого жидким азотом. Быстродействие фотодетектора составляло порядка $100 \mathrm{~ns}$. Сигнал фотоприемника измерялся импульсным синхронным детектором BoxCar SR250 с синхронизацией по импульсам тока с многократным 


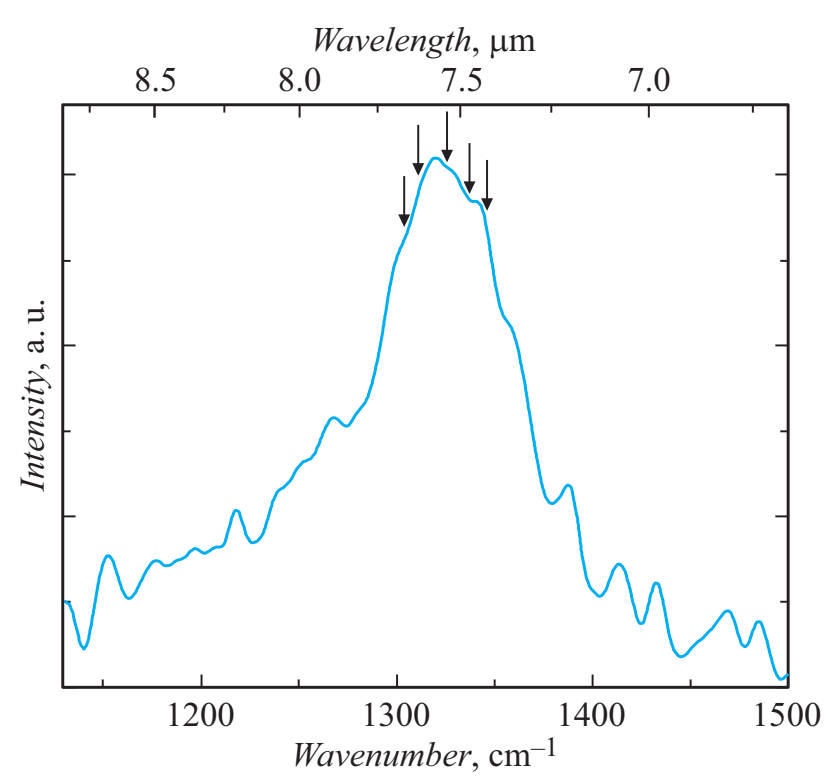

Рис. 1. Спектр спонтанного излучения, измеренный при температуре $80 \mathrm{~K}$ в геометрии 4-сколотого образца. Результаты ранее отражены авторами в работе [14]. Стрелками отмечены центральные положения групп продольных мод, наблюдаемых в спектрах лазерной генерации, представленных на рис. 3.

усреднением сигнала. Спектры стимулированного излучения измерялись в режиме пошагового сканирования с помощью фурье-спектрометра Bruker Vertex 80v. Спектральное разрешение составляло $0.2 \mathrm{~cm}^{-1}$. Вольтамперные характеристики измерялись при пропускании импульсов тока с длительностью $150 \mathrm{~ns}$ на частоте $10 \mathrm{kHz}$. Измерения были проведены в диапазоне температур $80-300 \mathrm{~K}$.

Спектр спонтанного излучения представлен на рис. 1. Максимум интенсивности электролюминесценции (ЭЛ) соответствует энергии кванта $163.6 \mathrm{meV}$. Малая ширина на полувысоте (FWHM) спектра ЭЛ (порядка $105 \mathrm{~cm}^{-1}$ ) свидетельствует о высоком оптическом качестве каскадов [20]. Вольт-амперная характеристика, а также зависимость интегральной интенсивности излучения от токовой накачки представлены на рис. 2. Пороговый ток составляет $0.51 \mathrm{~A}$, что соответствует пороговой плотности тока $1.5 \mathrm{kA} / \mathrm{cm}^{2}$. Скачки на зависимости интегральной интенсивности излучения от уровня накачки обусловлены перераспределением модового состава излучения (рис. 3). Падение интенсивности лазерной генерации наблюдается при напряжении свыше $18 \mathrm{~V}$, что соответствует величине удвоенного порогового напряжения $U_{t h}$

Спектры лазерной генерации при различных уровнях накачки представлены на рис. 3. На пороге генерации (соответствует $U_{t h}=9.0 \mathrm{~V}$ ) наблюдается многомодовый спектр генерации вблизи $1336 \mathrm{~cm}^{-1}$ (см. вставку на рис. 2), что отвечает положению коротковолнового „Плеча“ в спектре ЭЛ (рис. 1). Увеличение напряжения до $10.5 \mathrm{~V}$ приводит к возникновению второй группы про- дольных мод вблизи $1325 \mathrm{~cm}^{-1}$. Дальнейшее увеличение уровня накачки до $14.8 \mathrm{~V}$ приводит к подавлению интенсивности группы мод вблизи $1336 \mathrm{~cm}^{-1}$ и росту интенсивности набора мод вблизи $1325 \mathrm{~cm}^{-1}$. При $U=16.1 \mathrm{~V}$ возникает набор мод вблизи $1311 \mathrm{~cm}^{-1}$. Дальнейший рост напряжения до $18.2 \mathrm{~V}$ приводит к дополнительному набору продольных мод вблизи $1302 \mathrm{~cm}^{-1}$. При уровне накачки более $20 \mathrm{~V}$ наблюдается понижение интенсивности длинноволновых составляющих в спектре генерации,

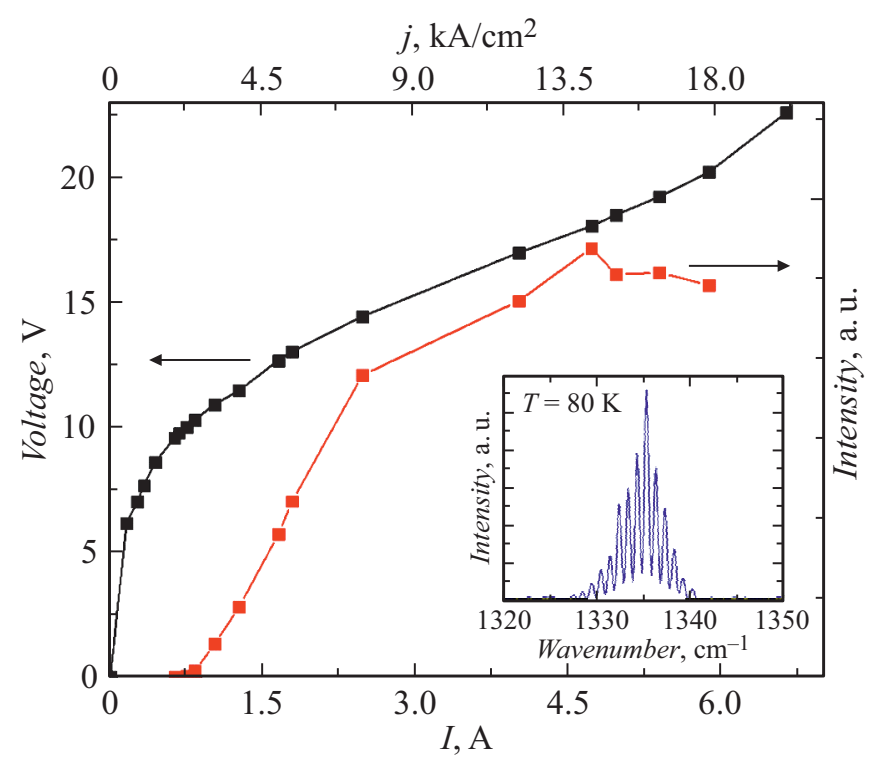

Рис. 2. Вольт-амперная характеристика (левая ось) и зависимость интегральной интенсивности излучения от токовой накачки (правая ось) для кристалла ККЛ в полосковой геометрии, измеренные при температуре $80 \mathrm{~K}$. На вставке - спектр лазерной генерации при рабочем напряжении $9 \mathrm{~V}$.

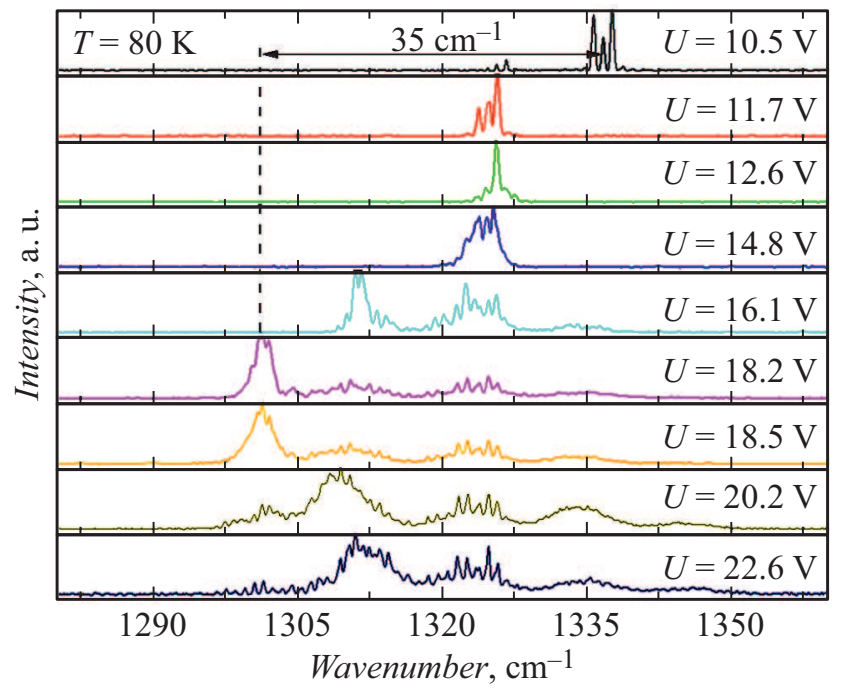

Рис. 3. Спектры лазерной генерации (нормированные по интенсивности) при различных рабочих напряжениях. Спектры измерены при температуре $80 \mathrm{~K}$. 
а также возникновение дополнительного набора мод вблизи $1345 \mathrm{~cm}^{-1}$.

С увеличением температуры ККЛ диапазон перераспределения интенсивности в спектре генерации под действием управляющего напряжения уменьшается (составляет 10 и $5 \mathrm{~cm}^{-1}$ при температуре 160 и $210 \mathrm{~K}$ соответственно). При температуре $300 \mathrm{~K}$ спектрального сдвига излучения ККЛ при изменении напряжения не продемонстрировано. Многомодовая генерация наблюдается вблизи $7.8 \mu \mathrm{m}$ со значением FWHM порядка 20-30 nm.

Спектральный сдвиг излучения ККЛ при изменении управляющего напряжения обычно связывают с эффектом Штарка [10-12], в котором диапазон перестройки пропорционален пространственному расстоянию между волновыми функциями верхнего и нижнего уровней [12]. Как следствие, в использованной в настоящей работе схеме активной области на основе двухфононного опустошения нижнего уровня диапазон перераспределения интенсивности в спектре генерации меньше, чем в случае применения конструкций активных областей на основе диагональных излучательных переходов [11,12].

Суммируя, в ходе работы продемонстрировано перераспределение интенсивностей коротковолновых и длинноволновых компонент в пределах полосы усиления в спектре генерации ККЛ под действием управляющего напряжения. Использована конструкция активной области на основе двухфононного опустошения нижнего уровня. Спектральный сдвиг излучения ККЛ при $80 \mathrm{~K}$ составил $200 \mathrm{~nm}\left(\sim 35 \mathrm{~cm}^{-1}\right)$. Максимальная ширина спектра генерации порядка $300 \mathrm{~nm}\left(\sim 50 \mathrm{~cm}^{-1}\right)$. В дальнейшем применение внешнего резонатора с перестраиваемым резонансным фильтром позволит осуществить прецизионное управление длиной волны излучения данного типа ККЛ.

\section{Финансирование работы}

Работа выполнена при финансовой поддержке Российского фонда фундаментальных исследований в рамках научного проекта № 16-29-09580. Д.А. Фирсов, Л.Е. Воробьев благодарят за частичную поддержку исследований Минобрнауки РФ (государственные задания № 3.933.2017/4.6 и 3.6153.2017/7.8).

\section{Конфликт интересов}

Авторы заявляют, что у них нет конфликта интересов.

\section{Список литературы}

[1] Michel A.P.M., Kapit J., Witinski M.F., Blanchard R. // Appl. Opt. 2017. V. 56. P. E23-E29. DOI: 10.1364/ao.56.000e23

[2] Zimmermann H., Wiese M., Fiorani L., Ragnoni A. // J. Sens. Sens. Syst. 2017. V. 6. P. 155-161.

DOI: 10.5194 /jsss-6-155-2017
[3] Gmachl C., Capasso F., Sivco D.L., Cho A.Y. // Rep. Prog. Phys. 2001. V. 64. P. 1533-1601. DOI: $10.1088 / 0034-4885 / 64 / 11 / 204$

[4] Sharpe S.W., Kelly J.F., Hartman J.S., Gmachl C., Capasso F., Sivco D.L., Baillargeon J.N., Cho A.Y. // Opt. Lett. 1998. V. 23. P. 1396-1398. DOI: 10.1364/ol.23.001396

[5] Maulini R., Beck M., Faist J., Gini E. // Appl. Phys. Lett. 2004. V. 84. P. 1659-1661. DOI: 10.1063/1.1667609

[6] Faist J., Beck M., Aellen T., Gini E. // Appl. Phys. Lett. 2001. V. 78. P. 147-149. DOI: $10.1063 / 1.1339843$

[7] Gmachl C., Sivco D.L., Colombelli R., Capasso F., Cho A.Y. // Nature. 2002. V. 415. P. 883-887. DOI: $10.1038 / 415883 a$

[8] Müller A., Beck M., Faist J., Oesterle U., Ilegems M. // Appl. Phys. Lett. 1999. V. 75. P. 1509-1511. DOI: 10.1063/1.124738

[9] Teissier J., Laurent S., Manquest C., Sirtori C., Bousseksou A., Coudevylle J.R., Colombelli R., Beaudoin G., Sagnes I. // Opt. Express. 2012. V. 20. P. 1172-1183. DOI: $10.1364 /$ oe. 20.001172

[10] Yao Y., Franz K.J., Wang X., Fan J.-Y., Gmachl C. // Appl. Phys. Lett. 2009. V. 95. P. 021105. DOI: 10.1063/1.3179165

[11] Yao Y., Liu Z., Hoffman A.J., Franz K.J., Gmachl C.F. // IEEE J. Quant. Electron. 2009. V. 45. P. 730-736. DOI: 10.1109 /jqe.2009.2013122

[12] Bismuto A., Terazzi R., Beck M., Faist J. // Appl. Phys. Lett. 2010. V. 96. P. 141105 . DOI: $10.1063 / 1.3377008$

[13] Young C., Cendejas R., Howard S.S., Sanchez-Vaynshteyn W., Hoffman A.J., Franz K.J., Yao Y., Mizaikoff B., Wang X., Fan J., Gmachl C.F. // Appl. Phys. Lett. 2009. V. 94. P. 091109. DOI: $10.1063 / 1.3093422$

[14] Babichev A.V., Gladyshev A.G., Kolodeznyi E.S., Kurochkin A.S., Sokolovskii G.S., Bougrov V.E., Karachinsky L.Ya., Novikov I.I., Dudelev V.V., Nevedomsky V.N., Slipchenko S.O., Lutetskiy A.V., Sofronov A.N., Firsov D.A., Vorobjev L.E. // J. Phys.: Conf. Ser. 2018. V. 1124. P. 041029. DOI: $10.1088 / 1742-6596 / 1124 / 4 / 041029$

[15] Бабичев А.В., Курочкин А.С., Колодезный Е.С., Филимонов А.В., Усикова А.А., Неведомский В.Н., Гладымев А.Г., Карачинский Л.Я., Новиков И.И., Егоров А.Ю. // ФТП. 2018. Т. 52. В. 6. С. 597-602. DOI: $10.21883 /$ FTP.2018.06.45922.8751

[16] Бабичев А.В., Гладышев А.Г., Курочкин А.С., Колодезный Е.С., Соколовский Г.С., Бугров В.Е., Карачинский Л.Я., Новиков И.И., Bousseksou A., Егоров А.Ю. // ФТП. 2018. Т. 52. В. 8. С. 954-957. DOI: $10.21883 /$ FTP.2018.08.46226.8834

[17] Бабичев А.В., Гладышев А.Г., Филимонов А.В., Неведомский В.Н., Курочкин А.С., Колодезный Е.С., Соколовский Г.С., Бугров В.Е., Карачинский Л.Я., Новиков И.И., Bousseksou A., Егоров А.Ю. // Письма в ЖТФ. 2017. Т. 43. B. 14. C. 64-71. DOI: 10.21883/PJTF.2017.14.44833.16776

[18] Бабичев А.В., Дюделев В.В., Гладышев А.Г., Михайлов Д.А., Курочкин А.С., Колодезный Е.С., Бугров В.Е., Неведомский В.Н., Карачинский Л.Я., Новиков И.И., Денисов Д.В., Ионов А.С., Слипченко С.О., Лютецкий А.В., Пихтин Н.А., Соколовский Г.С., Егоров А.Ю. // Письма в ЖТФ. 2019. Т. 45. В. 14. С. 48-51. DOI: $10.21883 /$ PJTF.2019.14.48025.17824

[19] Бабичев А.В., Bousseksou А., Пихтин Н.А., Тарасов И.С., Никитина Е.В., Софронов А.Н., Фирсов Д.А., Воробьев Л.Е., Новиков И.И., Карачинский Л.Я., Егоров А.Ю. // ФТП. 2016. Т. 50. В. 10. С. 1320-1324. DOI: $10.1134 / \mathrm{s} 1063782616100067$

[20] Hofstetter D., Beck M., Aellen T., Faist J. // Appl. Phys. Lett. 2001. V. 78. P. 396-398. DOI: $10.1063 / 1.1340865$ 